\title{
Abiotic controls and temporal variability of river metabolism: multiyear analyses of Mississippi and Chattahoochee River data
}

\author{
Walter K. Dodds ${ }^{1,3}$, Allison M. Veach ${ }^{1,4}$, Claire M. Ruffing ${ }^{2,5}$, \\ Danelle M. Larson $^{1,6}$, Jason L. Fischer ${ }^{1,7}$, AND Katie H. Costigan ${ }^{2,8}$ \\ ${ }^{1}$ Division of Biology, Kansas State University, Manhattan, Kansas 66506 USA \\ ${ }^{2}$ Department of Geography, Kansas State University, Manhattan, Kansas 66506 USA
}

\begin{abstract}
Whole-ecosystem metabolism is an important indicator of the role of organic matter, C cycling, and trophic structure in rivers. Ecosystem metabolism is well studied in small streams, but less is known about metabolism in large rivers. We estimated daily whole-ecosystem metabolism over 2 y for 1 site each at the Mississippi and Chattahoochee Rivers in the USA to understand factors influencing temporal patterns of ecosystem metabolism. We estimated rates of gross primary production (GPP), community respiration (CR), and net ecosystem production (NEP) with a curve-fitting approach with publicly available discharge $(\mathrm{Q})$, dissolved $\mathrm{O}_{2}$, temperature, and photosynthetically active radiation (PAR) data. Models were run for week-long blocks, and power analyses suggested that rates should be established at least once for each 10-wk period throughout the year to characterize annual rates of metabolism accurately in these 2 rivers. We analyzed weekly rates averaged over 10-wk periods with Spearman rank correlation to identify potential drivers and with path analyses to identify interactions among variables driving GPP, $\mathrm{CR}$, and NEP. Both rivers had an overall negative NEP, and the Mississippi River had stronger seasonal trends. In the Mississippi River, CR was strongly positively correlated with $Q$, which suggests variation in seasonal availability of allochthonous $\mathrm{C}$. In the Chattahoochee, $\mathrm{CR}$ was most strongly positively correlated with GPP, whereas GPP was negatively correlated with Q, which suggests that autochthonous processes and water-column light attenuation played important roles in $C$ dynamics. Our results suggest that these large rivers were net heterotrophic at annual time scales but autotrophy can be important seasonally.
\end{abstract}

Key words: metabolism, primary production, large river, respiration, net ecosystem production, net primary production.

Rivers are a significant component of the global C cycle. Conservative estimates indicate that rivers release $0.23 \mathrm{Pg} \mathrm{C} / \mathrm{y}$ into the atmosphere in addition to transporting $0.71 \mathrm{Pg} \mathrm{C} / \mathrm{y}$ to oceans (Cole and Caraco 2001, Cole et al. 2007). Rivers are not simply pipes to the ocean. Metabolic rates in rivers influence their biogeochemical role and how they function to transport material (Battin et al. 2009).

Ecosystem metabolism can be characterized by net ecosystem production (NEP), which is the balance of gross primary production (GPP) and community respiration (CR; Bott 2006). NEP indicates the balance

\footnotetext{
${ }^{3}$ E-mail addresses: wkdodds@k-state.edu

4 amveach@k-state.edu

${ }^{5}$ cruffing@k-state.edu

6 daneller@ksu.edu

7 fisch133@gmail.com

8 costigan@k-state.edu
}

of allochthonous and autochthonous energy sources of a given system and roughly indicates if the system is a net producer or consumer of $\mathrm{C}$ (though accounting for $\mathrm{O}_{2}$ does not reflect anaerobic metabolic processes, such as fermentation and denitrification; Dodds and Cole 2007). Components of ecosystem metabolism provide direct metrics for assessing the role of organic-matter sources, C flow, and the trophic structure of flowing waters (Dodds 2007) and can be a good indicator of ecosystem health (Fellows et al. 2006). Many estimates of rates of GPP, CR, and NEP are available for wadeable streams (e.g., Bernot et al. 2010, Tank et al. 2010). Less is known about GPP in large rivers, even though GPP probably is important in some riverine food webs (e.g., Thorp and Delong 2002) and certainly is important in streams (e.g., Marcarelli et al. 2011). Few detailed, long-term estimates of whole-system metabolism exist for rivers, but continuous data for streams document consider- 


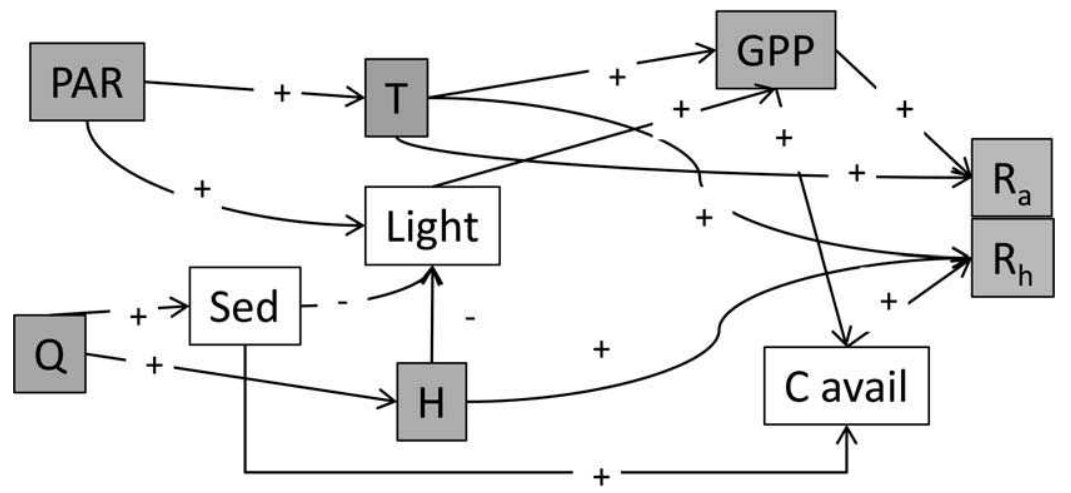

FIG. 1. A conceptual model of the hypothesized drivers of river metabolism. GPP $=$ gross primary production, $\mathrm{R}_{\mathrm{a}}=$ autotrophic component of community respiration, $\mathrm{R}_{\mathrm{h}}=$ heterotrophic component of community respiration, PAR (upper line) $=$ photosynthetically available radiation at the water's surface, $\mathrm{Q}=$ discharge, $\mathrm{H}=$ water column depth, $\mathrm{T}=$ water temperature, PAR (lower line) = photosynthetically active radiation in the water column, Sed = suspended sediment concentration, and C avail $=\mathrm{C}$ availability for community heterotrophic respiration. Signs give a hypothesized direction of interaction. See text for rationale for hypotheses. Shaded boxes indicate variables measured directly or modeled for our study. $R_{a}$ and $R_{h}$ cannot be separated with our methods.

able annual variability (Roberts et al. 2007). Thus, understanding of ecosystem metabolism dynamics within large rivers is limited.

Several abiotic controls on GPP and CR are known, with empirical support primarily derived from research on small streams. These controls include light (Naiman 1983, Mulholland et al. 2001, Acuña et al. 2004, Bott 2006), temperature (Sinsabaugh 1997, Demars et al. 2011), nutrients (McTammany et al. 2007, Bernot et al. 2010), and organic-matter supply (Young and Huryn 1999, McTammany et al. 2007). These authors used the River Continuum Concept (RCC; Vannote et al. 1980) to predict patterns in these drivers of GPP and CR along stream corridors, and the general predictions have been verified in small-tomedium streams (e.g., Webster et al. 1995, Bott et al. 2006, Uehlinger 2006). The RCC framework suggests that large rivers $\left(>7^{\text {th }}\right.$ order) in the network should be predominantly heterotrophic because of light limitation caused by increases in turbidity and depth and by transmitted organic-matter subsidies from upstream. The RCC also suggests that phytoplankton might be important in large rivers, and recent research has substantiated the importance of riverine autotrophs in some cases (e.g., Oliver and Merrick 2006).

Even less is known about how the balance of GPP and $C R$ varies annually in rivers, although seasonal variation requires estimation of system metabolism throughout the year to estimate annual production (Wetzel 2001). Empirical evidence exists for seasonal fluctuations in metabolism in rivers with discharge $\leq 500 \mathrm{~m}^{3}$ /s (e.g., Naiman 1983, Minshall et al. 1992, Oliver and Merrick 2006, Colangelo 2007), but worldwide, many rivers have discharges several orders of magnitude greater than the largest of the studied rivers.

We investigated the annual metabolic characteristics of the Chattahoochee River (mean annual discharge at study point $\sim 100 \mathrm{~m}^{3} / \mathrm{s}$ ) and the Mississippi River (mean annual discharge at study point $\sim 18,000 \mathrm{~m}^{3} / \mathrm{s}$ ) to understand better the temporal patterns and drivers associated with metabolism in a medium and a large river. Our objective was to assess the effects of light (as photosynthetically active radiation $[P A R])$, temperature $(T)$, and discharge $(\mathrm{Q})$ on GPP and CR over annual time scales. We assumed that nutrients are abundant in larger rivers but did not assess the effects of nutrients because of lack of available data for the Chattahoochee River. Our central hypotheses are guided by the drivers shown to control ecosystem metabolism in smaller systems (Fig. 1), including PAR, Q, depth (H), C availability from GPP, and T.

We predicted that light availability for photosynthesis would be positively correlated with GPP and driven by PAR and turbidity resulting from suspended sediment and inversely related to the $\mathrm{H}$ from light attenuation. CR includes both heterotrophic and autotrophic components. We predicted the autotrophic component would be positively related to GPP and $\mathrm{T}$ and the heterotrophic component to be positively influenced by $\mathrm{C}$ availability and $\mathrm{T}$, with $\mathrm{C}$ availability increased by GPP and organic loading. If heterotrophic activity in the water column (as opposed to being associated with the benthic zone) is important, then greater $\mathrm{H}$ will increase the volume of water over each square meter and, therefore, 
TABLE 1. Site characteristics of the Chattahoochee and Mississippi River stations from water years 2007-2010. Total N $(n=45)$, total P $(n=45)$, total $C(n=45)$, and suspended sediment $(n=44)$ measurements typically were taken 1 to 2 times/mo throughout the study period in the Mississippi River. No water-chemistry data were available for the Chattahoochee River (=NA). $\mathrm{Q}=$ discharge, $\mathrm{T}=$ temperature, $\mathrm{H}=$ depth of the water column, $\max =$ maximum, $\min =$ minimum.

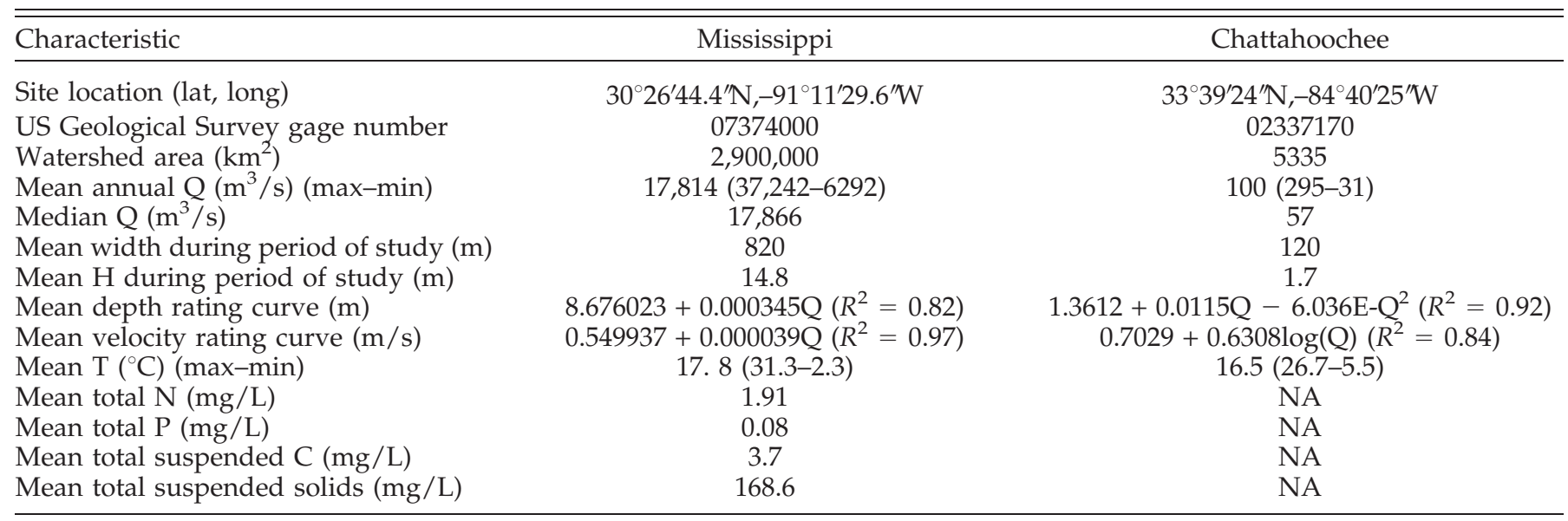

increase CR when expressed per unit area. We also predicted that increases in T would increase GPP and CR because $\mathrm{T}$ influences lotic metabolic rates (Wiley et al. 1990, Mulholland et al. 2001, Bott 2006). Last, we predicted that $\mathrm{Q}$ would be negatively correlated with GPP because it is associated with increases in $\mathrm{H}$ and turbidity, which lowers light penetration, and has the potential for scouring benthic producers and flushing planktonic producers. We expected all of these factors to vary seasonally. Thus, we modeled 2 to $3 \mathrm{y}$ of data from each river to assess differences in temporal patterns, metabolic rates, and annual production between the 2 rivers.

\section{Methods}

\section{Site details and base data}

We selected the Chattahoochee River and the Mississippi River (see site information in Table 1) because each had $Q$ greater than most previously studied systems, had available continuous annual data for $Q$, dissolved $\mathrm{O}_{2}$, and $\mathrm{T}$, and were within $100 \mathrm{~km}$ of a solar irradiance monitoring station. The data-collection site on the Chattahoochee was $>50 \mathrm{~km}$ from major tributaries or impoundments and on the Mississippi was $>1000 \mathrm{~km}$ downstream of the nearest dam or lock. $\mathrm{Q}, \mathrm{O}_{2}$, and $\mathrm{T}$ were measured at 15-min intervals from 1 October 2008 to 30 September 2010 at the Chattahoochee River site and at 60-min intervals from 1 October 2007 to 30 September 2010 at the Mississippi River site. These data were provided by the US Geological Survey (USGS; www.usgs.gov). The sensors were deployed in the main channel and were calibrated for dissolved $\mathrm{O}_{2}$ according to USGS continuous water-quality monitoring protocol (see
Lewis 2005). Data for PAR were collected from the respective periods of record from US Department of Agriculture ultraviolet B (UV-B) monitoring stations $<100 \mathrm{~km}$ of each site (Chattahoochee River, Griffin, Georgia; Mississippi River, Baton Rouge, Louisiana). We used daily barometric pressure to calculate reaeration rates and collected these data for the respective time periods at each gage site (Chattahoochee River, Fairburn, Georgia; Mississippi River, Baton Rouge, Louisiana) from the Weather Underground archives (www.wunderground.com).

We derived rating curves from both sites using online USGS data for width, H, Q, and average velocity (U) for model calculations. Daily estimates of $\mathrm{Q}$ are based on gage height, but $\mathrm{H}$ is linked to $\mathrm{Q}$ only at times when rating curves (multiple measures of $\mathrm{H}$ and $\mathrm{U}$ ) are established for the monitoring site. We used USGS channel-survey data from online information provided for each site (http://waterdata.usgs. gov $/$ nwis / measurements?site_no $=07374000 \& a g e n c y$ _ $\mathrm{cd}=$ USGS\&format $=\mathrm{html}$ _table_expanded; http:/ / water data.usgs.gov/nwis/measurements?site_no $=02337170 \&$ agency_cd $=$ USGS\&format $=h$ tml_table_expanded) for multiple values of $Q$ at each site to back-calculate $H$ for each day from mean daily $Q$. We used data from the Chattahoochee River from January 1985 to August 2011 and the Mississippi River from March 2004 to December 2011 to establish these rating curves. Significant best-fit equations can be found in Table 1. We back-calculated $U$, required for estimating reaeration rates $\left(K_{\mathrm{a}}\right)$, from $\mathrm{Q}$ with linear regression. These relationships were highly significant.

Over the 2-y data set for the Chattahoochee River, $3 \%$ of the data (a total of $18 \mathrm{~d}$ ) were missing. The 
Mississippi River data set was missing $\sim 14 \%$ of the data $(151 \mathrm{~d})$ over the 3-y data period. Only days with a complete data set were used for modeling unless they were missing only a few time periods (periods of 15 or $60 \mathrm{~min}$ for the Chattahoochee and the Mississippi River, respectively), in which case, we assumed that missing values were the mean of the values before and after the gap.

\section{Metabolism modeling}

We used a curve-fitting approach similar to that described by Holtgrieve et al. (2010) with the general equations and approach delineated by Riley and Dodds (2013), except that we used a single-station method. We did not trust modeling $K_{\mathrm{a}}$ during many periods because we lacked a diurnal $\mathrm{O}_{2}$ pattern or found strong temporal (multiday) lags in $\mathrm{O}_{2}$ patterns (e.g., a series of cloudy days leading to progressively lower $\mathrm{O}_{2}$; data not shown). The basic approach to Holtgrieve's model is to adjust rates of GPP and CR based on the measured physical characteristics of the stream ( $\mathrm{H}$ and $\mathrm{T}$ ) and the environment (PAR and atmospheric pressure) to predict diel trends in $\mathrm{O}_{2}$. Standard methods for calculating GPP, CR, and NEP directly (e.g., Marzolf et al. 1994, 1998, Young and Huryn 1998) are not appropriate for larger rivers because equilibration across the large depth of water can cause significant time lags in diurnal $\mathrm{O}_{2}$ swings (data not shown), making estimation of nighttime CR impossible. The model corrects CR and GPP for diurnal changes in $\mathrm{T}$, but $\mathrm{T}$ does not change substantially over most days or even weeks in large rivers because of the thermal buffering capacity of such large volumes of water.

We calculated $K_{a}$, (/d) with the equation of Isaacs and Gaudy (1968):

$$
K_{a}=4.7531\left(\frac{\mathrm{U}}{\mathrm{H}^{1.5}}\right) 1.0241^{\mathrm{T}-20}
$$

This method was developed for flumes, but it is a modified version of the method developed by Churchill et al. (1962) for large rivers and is the best performing method for calculating $K_{a}$ when only $\mathrm{H}$, $\mathrm{U}$, and $\mathrm{T}$ are known (Cox 2003).

We compared the observed concentration of $\mathrm{O}_{2}$ in the water column to the modeled $\mathrm{O}_{2}$ predicted by changing rates of $\mathrm{R}$ and GPP to minimize the sum of squared error between observed and modeled $\mathrm{O}_{2}$ concentration. The change in $\mathrm{O}_{2}$ concentration between each of 2 time periods of measurement $\left(t_{1}\right.$ and $t_{2}$ ) was calculated as

$$
\frac{\delta \mathrm{O}_{2}}{\delta t}=\frac{\delta \mathrm{O}_{2, \mathrm{GPP}}}{\delta t}+\frac{\delta \mathrm{O}_{2, \mathrm{CR}}}{\delta t}+\frac{\delta \mathrm{O}_{2, \mathrm{~K} a}}{\delta t}
$$

where $\mathrm{O}_{2, \mathrm{GPP}}$ is the change in $\mathrm{O}_{2}$ from $\mathrm{GPP}, \delta \mathrm{O}_{2, \mathrm{CR}}$ is the change in $\mathrm{O}_{2}$ from $\mathrm{CR}, \delta \mathrm{O}_{2, K a}$ is the change in $\mathrm{O}_{2}$ from $K_{\mathrm{a}}$, and change in time $(\delta t)$ is

$$
\delta t=t_{1}-t_{2}
$$

$\delta \mathrm{O}_{2, \mathrm{GPP}}$ is driven by the relationship between PAR and GPP, corrected for average temperature $\left(\mathrm{T}_{\mathrm{avg}}\right)$ with the combined equations by Jassby and Platt (1976) for photosynthetic rate and Parkhill and Gulliver (1999) for temperature correction.

$\delta \mathrm{O}_{2, \mathrm{GPP}}=$

$P_{\max } 1.036^{\left(\mathrm{T}_{\text {avg }}-20\right)} \tanh \left(\frac{\alpha\left[1.036^{\left(\mathrm{T}_{\text {avg }}-20\right)}\right] \mathrm{PAR}}{P_{\max }\left[1.036^{\left(\mathrm{T}_{\mathrm{avg}}-20\right)}\right]}\right) / \mathrm{H}$

where $P_{\text {max }}$ is maximum photosynthetic rate per unit area and $\alpha$ is the areal rate as influenced by PAR. In exploratory modeling, we found that the models were insensitive to initial values of $P_{\max }$, so in all models we set $P_{\max }$ to a high value and solved only for $\alpha$. We calculated the temperature-corrected CR (Parkhill and Gulliver 1999) as

$$
\delta \mathrm{O}_{2, \mathrm{CR}}=\mathrm{CR}\left(1.045^{\left[\mathrm{T}_{\mathrm{avg}}-20\right]}\right) / \mathrm{H},
$$

and the temperature-corrected $K_{a}$ was used to calculate change in $\mathrm{O}_{2}$ concentration by aeration for each time period as

$$
\delta \mathrm{O}_{2, \mathrm{sat}}=K_{a}\left(\mathrm{O}_{2, \mathrm{sat}}-\mathrm{O}_{2}\right)
$$

where $\mathrm{O}_{2 \text {,sat }}$ is the predicted dissolved $\mathrm{O}_{2}$ concentration at $100 \%$ saturation at the water temperature during the time period.

We initially modeled entire weekly time periods to estimate a single value for $\mathrm{CR}$ and $\alpha$ through the entire period while accounting for changes in PAR, barometric pressure, and $\mathrm{T}$ during that time. We assessed modeling results graphically, and if there was a sharp divergence in observed and predicted values during the week (i.e., a large sum of squared error), we broke the data into time periods within which trends appeared to be similar. These more abrupt breaks tended to occur with high discharge events. We found that this approach of modeling multiple days gave better results than those obtained by modeling single days as others have done because it could account for time lags in these larger rivers 
(e.g., cumulative effects of progressively cloudier days; data not shown).

\section{Calculation of annual rates and statistical analysis}

We did initial assessments of relationships among metabolic rates and abiotic drivers with Spearman rank correlation because GPP data for the Mississippi River failed to meet normality assumptions of parametric analyses. We tested for multicollinearity among our predictor variables. We also were concerned by the possibility for temporal autocorrelation and assessed this possibility by offsetting the CR data by 1 to 12 wk (offset by 1, 2, 3...12 wk), and cross-correlating all the offsets with Spearman rank correlation. We also checked T, PAR, and $Q$ for autocorrelation. GPP data were characterized by numerous 0 values and not suitable for this analysis and T, PAR, and $\mathrm{Q}$ had similar autocorrelation structure to CR (not shown), so we assumed that autocorrelation of CR and GPP occurred over similar time periods. Autocorrelation indicated potential problems with using the weekly data to test for relationships between estimated metabolic rates and physical characteristics that might influence those rates. Thus, we used the results of the autocorrelation tests (see results) and averaged model results and measured abiotic values over $\sim 10$-wk periods (approximate because not exactly 1 wk was modeled every time). We used nonparametric correlation of mean values as a first approach to test the relationships hypothesized in Fig. 1. We used Statistica (version 10.0; StatSoft, Tulsa, Oklahoma) for these analyses.

We noticed an inverse parabolic data distribution when GPP was plotted against PAR for the Mississippi River, and statistical significance of this trend was verified by analyzing the upper $95 \%$ of the data with quantile regression with the significance of the $2^{\text {nd }}$-order term of a $2^{\text {nd }}$-order polynomial curve indicating the nonlinearity. Quantile regression can test for trends at any portion of a probability distribution and is not limited by normality assumptions, making it ideal for data that are not normally distributed and where response variables exhibit multiple slopes (i.e., unequal variation; Cade and Noon 2003). In our case, multiple 0 values of GPP precluded use of standard statistics to verify the significance of the parabolic relationship. We did this analysis with the package quantreg in $\mathrm{R}$ (version 2.13.2; R Project for Statistical Computing, Vienna, Austria; Koenker 2011). We analyzed relationships among normally distributed variables with linear regression analyses in Statistica.
We used path analyses to parse out the complex and interactive nature of many of the variables hypothesized to be interacting with GPP and CR (Fig. 1). We recognize that temporal autocorrelation can produce spurious results, but we could not accomplish the path analyses with the few data points remaining after $10-w k$ time averages. Therefore, we used our weekly rates for these analyses. Path analyses are useful for investigating relationships with embedded variables, but considering the potential for temporal autocorrelation, our results of these analyses should be taken with caution. We took the approach outlined by Meyers et al. (2006) and used the SEPATH module in Statistica. To verify path analysis results, we also used the package MuMIn in $\mathrm{R}$ (version 2.13.2; Bartoń 2012) to take an informationtheoretic approach (Akaike's Information Criterion [AIC]; Burnham and Anderson 2002) to our hypotheses. The 2 model-selection techniques generally agreed, so AIC results are not further reported here.

Annual metabolic rates were estimated by summing weekly modeled rates through each year. In cases where $<3 \mathrm{~d}$ were missing, we assumed that the rates in the day immediately before the data gap applied throughout the data gap. When gaps tended to be only a few days long at most, this assumption was appropriate. Several months of data were missing during the $2^{\text {nd }} y$ of the Mississippi data set, so we used only the $1^{\text {st }}$ and $3^{\text {rd }}$ years for calculating annual rates. Annual rates were the sum of all modeled weekly rates. We used power analyses in Statistica to assess how much sampling was necessary to characterize annual rates based on data from our 2 study rivers. We used additional data from previously published findings for comparison of annual productivity. In cases where the literature data were displayed graphically, we used the open source program Engauge (version 5.1; http://digitizer. sourceforge.net) to digitize data.

\section{Results}

Values of CR were temporally autocorrelated in both data sets (Fig. 2). In general, temporal autocorrelation became nonsignificant within a $10-\mathrm{wk}$ period. In the Chattahoochee, the probability associated with autocorrelation was $p>0.05$ at $9 \mathrm{wk}, p<0.05$ at $10 \mathrm{wk}$, and $p>0.05$ at $11 \mathrm{wk}$, so the trend averaged through the points roughly crossed the significance level at 10 wk. Values of CR for the Mississippi lost autocorrelation by $9 \mathrm{wk}$. Therefore, we averaged CR values over $10-w \mathrm{k}$ periods for correlation analyses of drivers. We also used running means and confidence intervals (CIs) calculated over $10 \mathrm{wk}$ to generate trend 


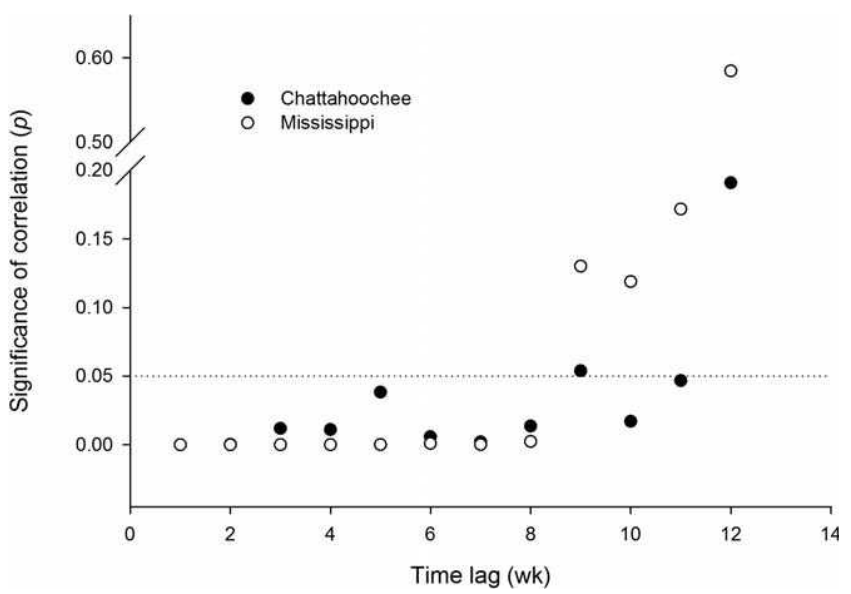

FIG. 2. Temporal autocorrelation of community respiration rates (CR) for the Chattahoochee River and the Mississippi River. Dashed line indicates $p=0.05$.

analyses and associated CIs for both data sets. Values of T, PAR, and Q also were temporally autocorrelated, and showed trends similar to those for CR (Fig. 2). Temporal autocorrelation in these abiotic variables was significant until $\sim 10 \mathrm{wk}$.

Values of CR, GPP, and NEP were temporally variable in both rivers (Figs $3 \mathrm{~A}-\mathrm{C}, 4 \mathrm{~A}-\mathrm{C}$ ). In the Chattahoochee River, CR and GPP were lower in winter 2010 than in the previous winter, but CIs overlapped (Fig. 4A, B). In general, daily NEP was closer to 0 in the Chattahoochee River than in the Mississippi River throughout the study period, but the running mean was always negative (Figs 3C, 4C). In the Mississippi River, the magnitude of variation was greater and the patterns were more distinct than in the Chattahoochee River. NEP was mostly negative, indicating that the rivers were consistently heterotrophic (Figs 3C, 4C). The Mississippi River generally had maximal $C R$ and negative NEP in spring and early summer during times of high $Q$ (Fig. 3A, C). GPP was generally $>0$ from late autumn through winter (Fig. 3B). In the Mississippi River, NEP mostly followed $C R$, but there were periods during the winter and early spring when the upper 95\% CI for NEP was close to or slightly $>0$ (Fig. 3C).

\section{Predictor variable associations with community respiration}

Metabolic trends and predictor relationships differed between the Chattahoochee and Mississippi Rivers (Tables 2, 3). In the Chattahoochee, CR was positively correlated with GPP $\left(R^{2}=0.68\right.$; Table 3$)$, but no other predictor variables were strongly correlated with CR (Table 3). In the Mississippi, CR was strongly positively correlated with $Q$ and PAR, but PAR and T covaried, making it difficult to discern
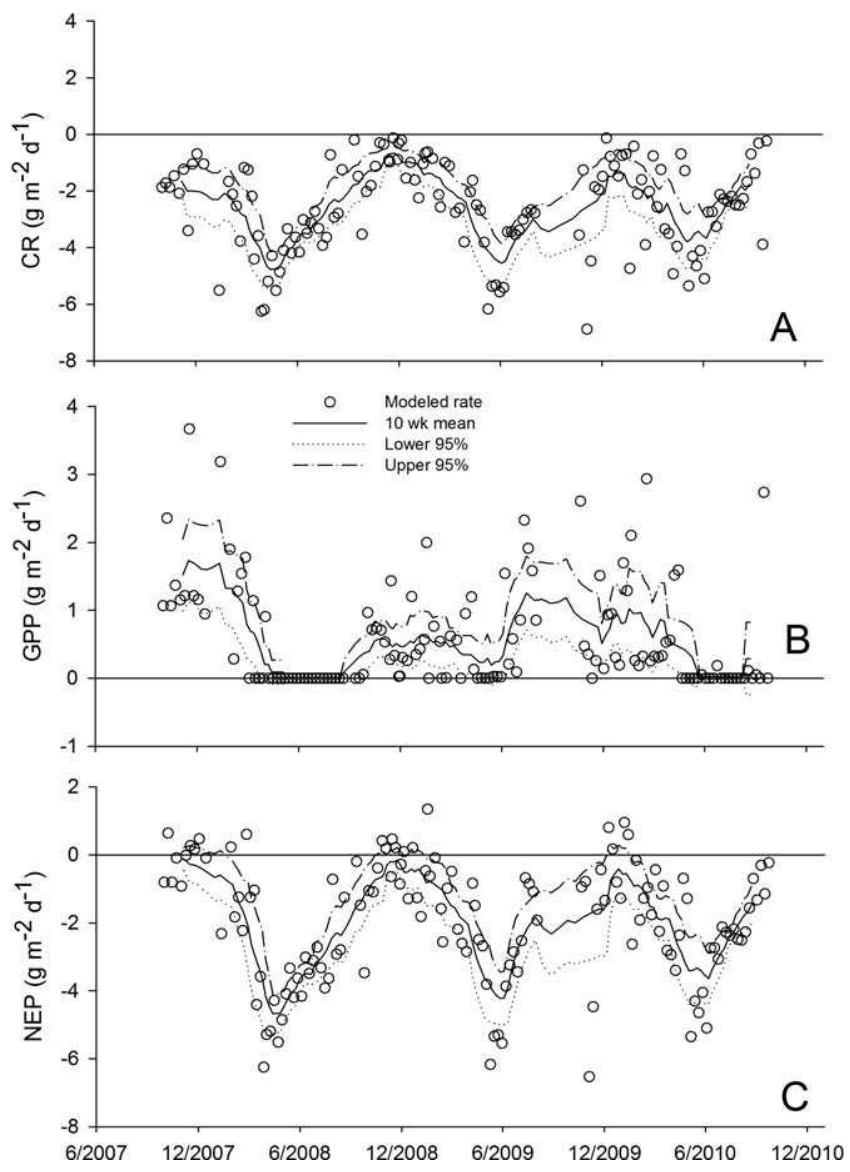

FIG. 3. Running mean and 95\% confidence interval taken over a 10-wk period (averaged across the data gap in autumn 2009) for community respiration (CR) (A), gross primary production (GPP) (B), and net ecosystem production (NEP) (C) for a 3-y period in the Mississippi River.

a causal effect (Table 2). Regression analyses indicated that $\mathrm{CR}$ was positively related to $\mathrm{Q}(\beta=0.65, p<$ $0.0001, R^{2}=0.41$ ). However, the increase in $\mathrm{CR}$ with $\mathrm{Q}$ is unlikely to be attributable solely to a deeper biologically active water column (more active planktonic biomass above each $\mathrm{m}^{2}$ ) because a $5 \times$ increase in $\mathrm{CR}$ corresponded to only a $2 \times$ increase in calculated $\mathrm{H}$.

\section{Predictor variable associations with GPP}

Responses of GPP varied between rivers (Fig. 5B, D). In the Chattahoochee, GPP often was low when $Q$ was high (Table 3, Fig. 5D). In the Mississippi, none of the predictor variables was strongly correlated with GPP (Table 2, Fig. 5A, B). Historical data show that total suspended solids and $\mathrm{Q}$ were significantly, positively related in both rivers (USGS data, results not shown; Dodds and Whiles 2004), suggesting that turbidity could interfere with GPP during times when $Q$ is elevated. 

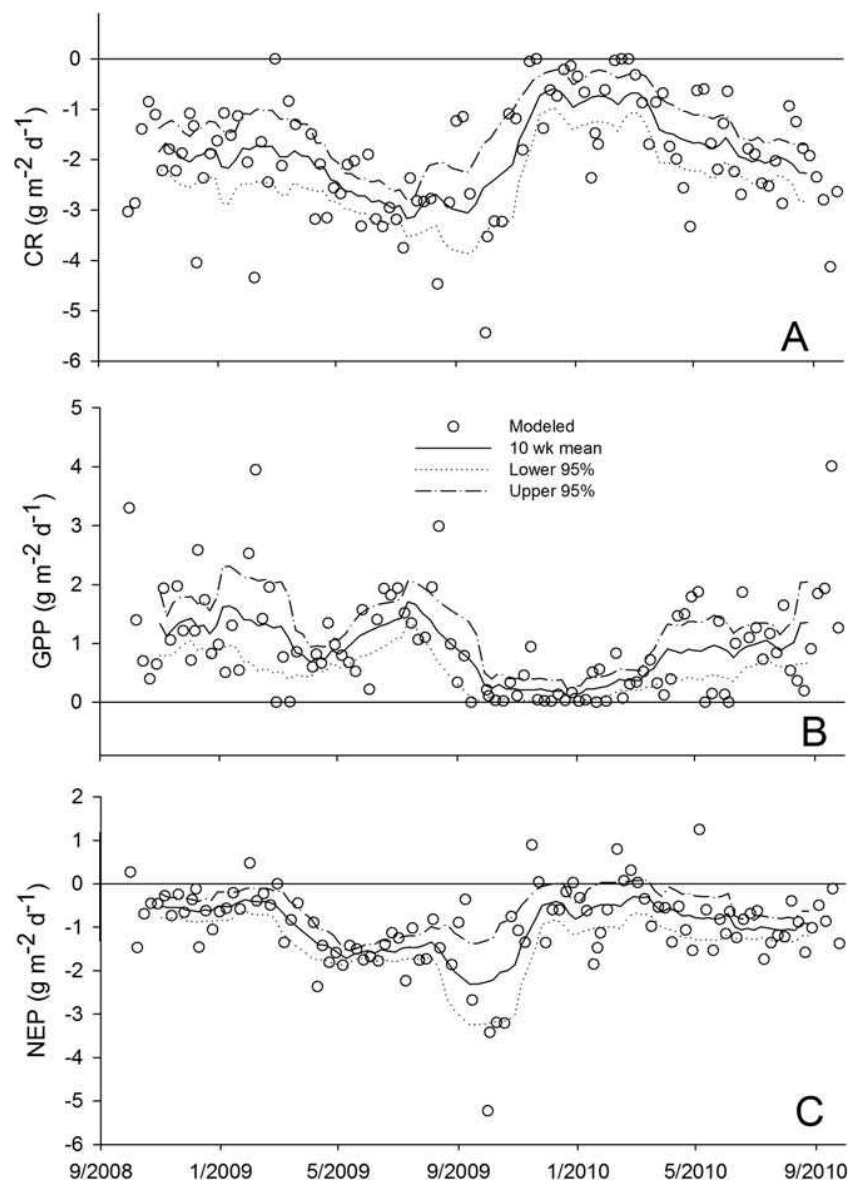

FIG. 4. Running mean and 95\% confidence interval taken over a 10-wk period for community respiration (CR) (A), gross primary production (GPP) (B), and net ecosystem production (NEP) (C) for a $2-y$ period in the Chattahoochee River.

GPP and PAR were not related in the Chattahoochee or the Mississippi (Tables 2, 3, Fig. 6A, B). However, the quantile regression indicated that GPP in the Mississippi River had a potential inverse

TABLE 2. Spearman rank correlation coefficients for 10wk means of modeled data in the Mississippi River. CR = community respiration (represented as a positive value), $\mathrm{GPP}=$ gross primary production, $\mathrm{NEP}=$ net ecosystem production, $\mathrm{Q}=$ discharge, $\mathrm{T}=$ temperature, $\mathrm{PAR}=$ photosynthetically active radiation. $n=14$. Bold values are significant at $p<0.05$.

\begin{tabular}{lrrrrrr}
\hline \hline & CR & GPP & NEP & Q & \multicolumn{1}{c}{ T } & PAR \\
\cline { 2 - 7 } CR & 1.00 & -0.28 & $\mathbf{- 0 . 8 7}$ & $\mathbf{0 . 7 5}$ & 0.20 & $\mathbf{0 . 7 4}$ \\
GPP & & 1.00 & $\mathbf{0 . 6 5}$ & -0.38 & -0.48 & -0.34 \\
NEP & & & 1.00 & $-\mathbf{0 . 7 1}$ & -0.37 & $-\mathbf{0 . 7 1}$ \\
Q & & & & 1.00 & -0.18 & 0.28 \\
T & & & & & 1.00 & $\mathbf{0 . 6 1}$ \\
PAR & & & & & & 1.00 \\
\hline
\end{tabular}

TABLE 3. Spearman rank correlation coefficients for 10wk means of modeled data in the Chattahoochee River. CR = community respiration (represented as a positive value), $\mathrm{GPP}=$ gross primary production, $\mathrm{NEP}=$ net ecosystem production, $\mathrm{Q}=$ discharge, $\mathrm{T}=$ temperature, $\mathrm{PAR}=$ photosynthetically active radiation. $n=11$. Bold values are significant at $p<0.05$.

\begin{tabular}{lrrrrrr}
\hline \hline & CR & GPP & NEP & Q & \multicolumn{1}{c}{ T } & PAR \\
\cline { 2 - 7 } CR & 1.00 & $\mathbf{0 . 6 8}$ & -0.41 & -0.59 & 0.60 & 0.54 \\
GPP & & 1.00 & 0.25 & $-\mathbf{0 . 8 5}$ & 0.35 & 0.53 \\
NEP & & & 1.00 & -0.21 & -0.59 & -0.29 \\
Q & & & & 1.00 & -0.32 & $-\mathbf{0 . 6 7}$ \\
T & & & & & 1.00 & $\mathbf{0 . 6 1}$ \\
PAR & & & & & & 1.00 \\
\hline
\end{tabular}

parabolic relationship to PAR at the $95^{\text {th }}$ percentile (Fig. 6A) because the $2^{\text {nd }}$-order term of the polynomial was significant $(p<0.05)$ at that percentile. The overall results suggest that seasonal factors may alter the total light reaching the primary producers in the river (i.e., light reaching the water surface does not necessarily penetrate through the water column). These factors could include cloud cover, low PAR during winter, increased $Q$ with high PAR in spring and summer, or periods of turbidity.

\section{Predictor variable associations across sites}

The path models (Fig. 7) indicate substantial differences between the Mississippi and Chattahoochee systems in response to external drivers and their coupling, but most of the results fit within the general framework of our initial conceptual model (Fig. 1). In general, the data suggest that $\mathrm{T}$ had a strong influence on GPP and CR in both rivers (although influence of $\mathrm{T}$ on GPP was negative in the Chattahoochee). PAR and $Q$ had a much more direct effect on GPP in the Chattahoochee than in the Mississippi. In the Chattahoochee, CR was driven by GPP, whereas in the Mississippi, CR was driven by $\mathrm{Q}$.

Path analyses of Chattahoochee data suggested that PAR had strong positive effects on GPP, but that Q and $\mathrm{T}$ had unexpected influences that were inconsistent with the correlation analyses. GPP had a positive effect on CR (as was also suggested in the correlation analysis), and T had a positive effect on CR (a result not seen in the correlation analysis).

Path analyses of Mississippi data suggested that PAR was negatively correlated with GPP, most likely because PAR was indirectly related to other seasonal effects, such as spring runoff and increased turbidity (i.e., maximum PAR reaching the water surface and highest $Q$ occurred in late and early summer). Increasing PAR did increase $\mathrm{T}$, and increasing PAR 


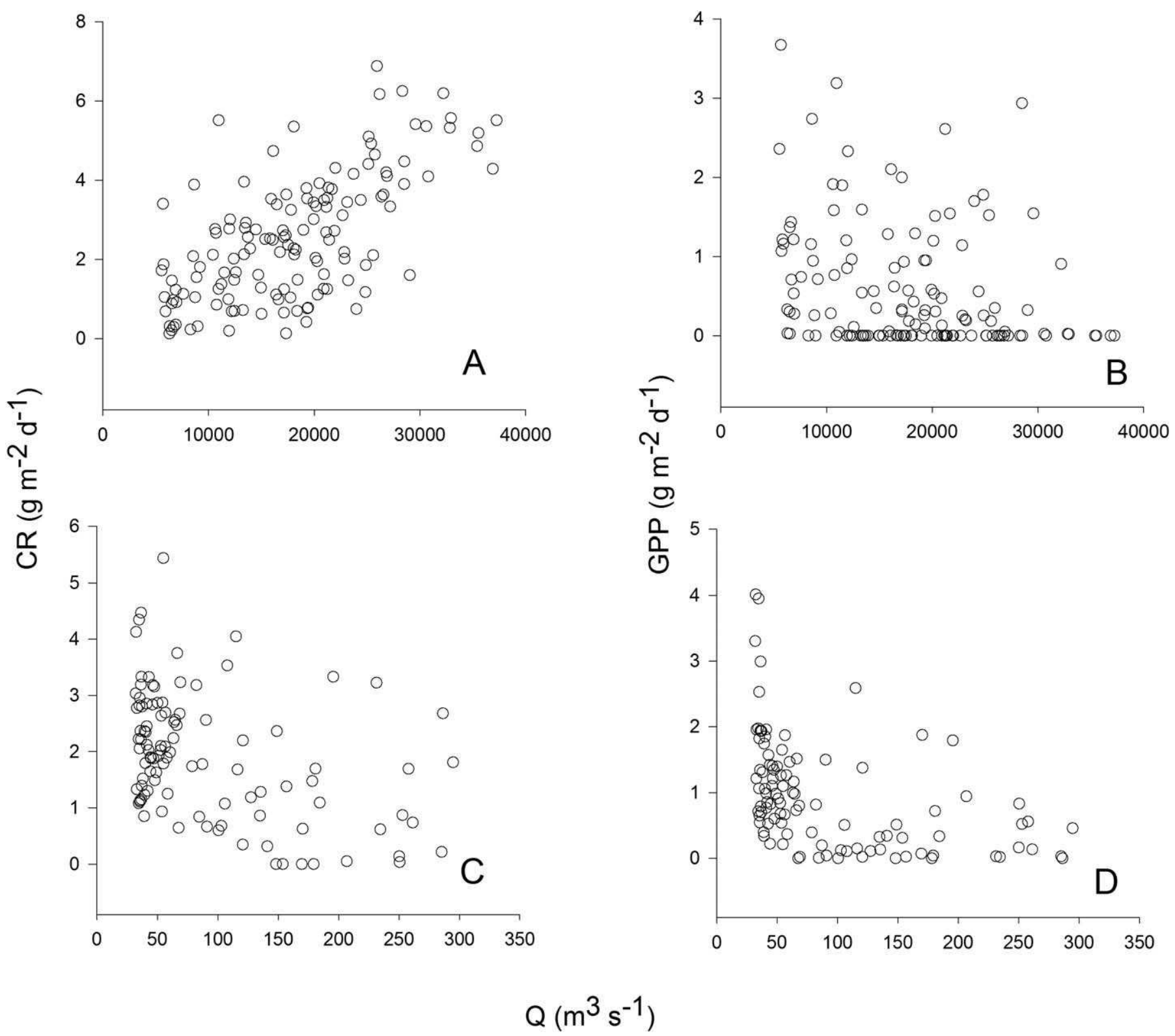

FIG. 5. Relationships of community respiration (CR) (A, C) and gross primary production (GPP) (B, D) to discharge (Q) in the Mississippi River (A, B) and Chattahoochee River (C, D). Each point represents an $\sim 1$-wk period.

did have a positive but indirect overall effect on GPP (Fig. 7). $T$ and $Q$ were the strongest drivers of $C R$ in the Mississippi, indicating that the model sorted out the cross-correlation between PAR and T (Table 2), and assigned $\mathrm{T}$ as more directly important than PAR to $\mathrm{CR}$.

\section{Annual estimates of metabolic rates}

For each river, we had $2 \mathrm{y}$ of data adequate to calculate annual metabolic rates. CR was slightly greater in the Mississippi than in the Chattahoochee, and mean GPP tended to be slightly lower in the
Mississippi than in the Chattahoochee (Table 4). However, NEP is the sum of GPP and CR, so annual NEP was significantly more negative $(\sim 2 \times)$ in the Mississippi than in the Chattahoochee. Both rivers showed interannual variation in CR and GPP and were lower in water-year 2008 than in water-year 2009 at both rivers, although the annual difference was more drastic in the Chattahoochee River.

\section{Discussion}

We modeled ecosystem metabolism continuously across years, which allowed us to compare GPP, CR, 


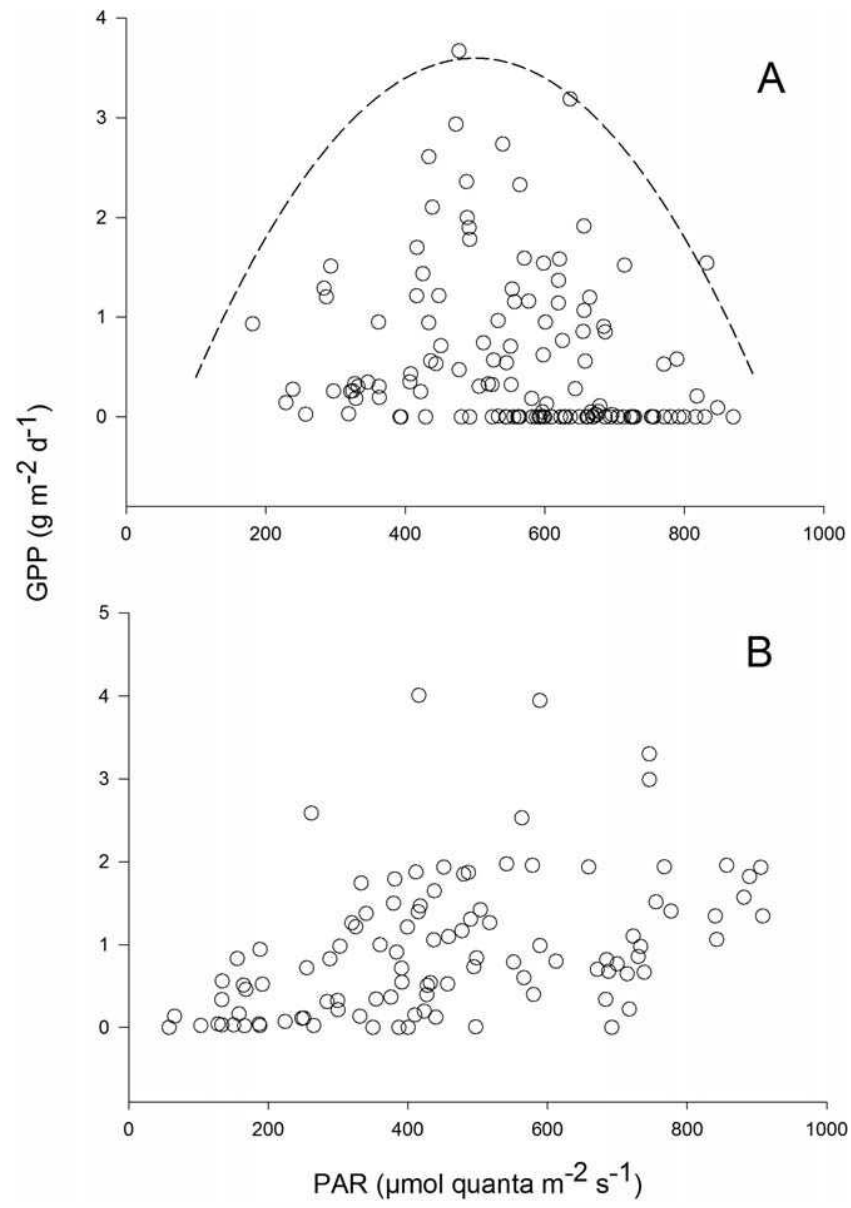

FIG. 6. Relationships of gross primary production (GPP) to mean light (as photosynthetically active radiation [PAR]) during the day over each modeled period in the Mississippi River (A) and Chattahoochee River (B). Each point represents an $\sim 1$-wk period. Dashed line in $\mathrm{A}$ is the significant relationship for the upper $95 \%$ indicated by quantile regression.

and NEP among seasonally changing drivers of ecosystem metabolism (PAR, T, and Q). Such analyses are rare for large rivers, and to our knowledge, such information is not available for rivers as large as the Mississippi. In general, the 2 rivers exhibited very different responses to abiotic drivers. Metabolic characteristics also differed between the sites, with GPP playing a much greater role in the Chattahoochee than in the Mississippi.

Reichert et al. (2009) suggested an analytical solution to calculate how upstream processes are influencing single-station estimates of metabolism. When we applied this calculation (a function of $U$ and $K_{a}$ ) to the Mississippi River, the result suggested that processes as far as 500 to $800 \mathrm{~km}$ upstream could be influencing $\mathrm{O}_{2}$ dynamics. The same calculation for the Chattahoochee suggested that processes $\sim 50 \mathrm{~km}$ upstream were integrated by the sampling station. Thus, even though our results do not cover the entire length of either river, they should represent a relatively long stretch of river.

Several potential sources of model error should be considered when interpreting our results. One complication is the ability of the aeration equation to assess $K_{\mathrm{a}}$ in these rivers accurately because CR and GPP are intimately tied to this value. $K_{\mathrm{a}}$ has been modeled by some (e.g., Dodds et al. 2008), and comparisons between modeling and directly measuring $K_{\mathrm{a}}$ indicate reasonable correlation between the 2 methods for small streams (Riley and Dodds 2013). Predicting $K_{\mathrm{a}}$ from modeling for large rivers is difficult because of the time lags inherent in large volumes of water (i.e., it can take days for $\mathrm{O}_{2}$ in the system to respond to changes in PAR). Thus, we used an equation to estimate $K_{\mathrm{a}}$. Such equations are used regularly to estimate effects of biochemical $\mathrm{O}_{2}$ demand (BOD) loading to rivers and, as such, have been relatively well tested in larger rivers (e.g., Cox 2003). A $2^{\text {nd }}$ source of error could be related to the ability to fit correct values of CR and GPP. We averaged over multiple fits across time to assess this source of error.

\section{$C R$}

Our results suggest that $Q$ had a strong stimulatory effect on CR expressed per unit area in the Mississippi. This effect could not be ascribed to a deeper water column (i.e., the increase in $\mathrm{CR}$ over the years was much greater than the increase in $H$ ), and we suspect that periods of high $Q$ correspond with greater supply rates of bioavailable $\mathrm{C}$. High $\mathrm{Q}$ also could supply higher concentrations of nutrients (e.g., Tank and Webster 1998). However, analyses of the 46 samples from the Mississippi by the USGS during the period of our study showed consistently high total $\mathrm{N}$ and $\mathrm{P}$ that was unrelated to gage height, and no relationship between gage height and dissolved organic C, BOD, or suspended C (data not shown). Chattahoochee nutrient data were not complete enough to establish relationships with $Q$ (stage height), and the single nutrient sample analyzed had modestly high $\mathrm{NO}_{3}{ }^{-}$and soluble reactive $\mathrm{P}$.

Several pieces of information suggest that most of the CR in these rivers and GPP in the Chattahoochee occur in the benthic zone and not in the water column. In the Mississippi, a $5 \times$ increase in $Q$ leads to only a $2 \times$ increase in $\mathrm{H}$ (in the area that is gaged), so at least a $2 \times$ increase in width accompanies such an increase in Q. Gaging stations tend to be in constricted areas, so average width probably increases much more 


\section{Mississippi}

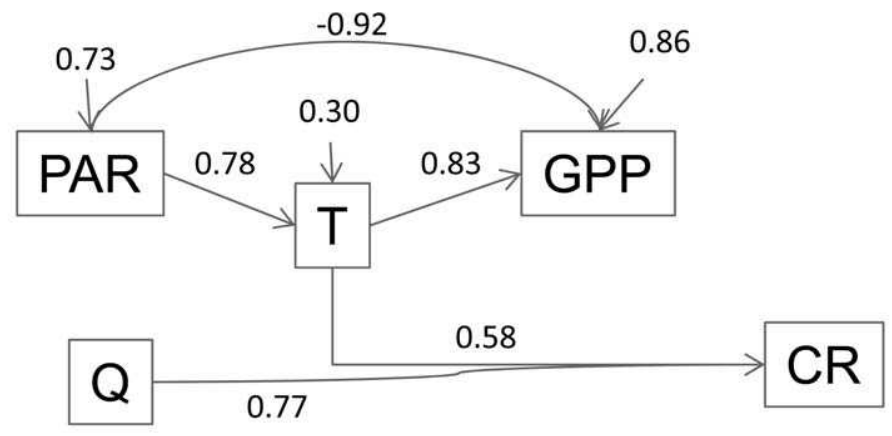

\section{Chattahoochee}

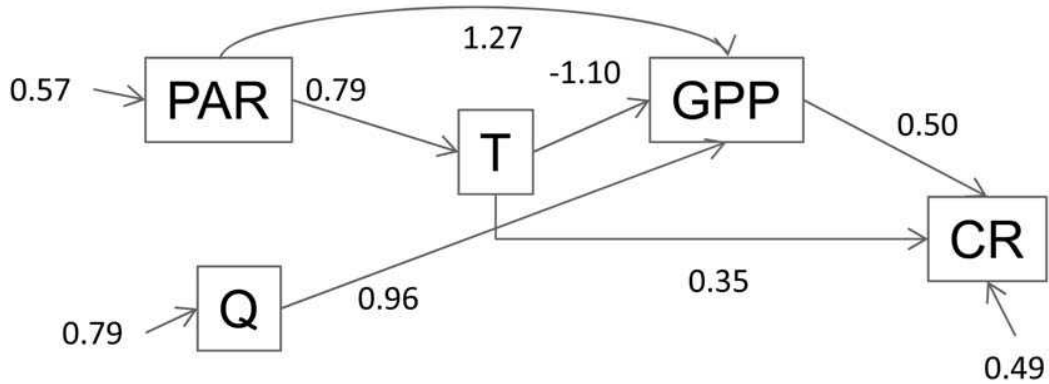

FIG. 7. Path analysis results of measured variables for the Mississippi River and the Chattahoochee River. Only statistically standardized values for path coefficients or error variances $(p<0.05)$ are shown. PAR $=$ photosynthetically available radiation, $\mathrm{T}=$ temperature, $\mathrm{Q}=$ discharge, $\mathrm{GPP}=$ gross primary production, $\mathrm{CR}=$ community respiration.

during periods of high $\mathrm{Q}$ in most, less constrained, areas of the river. Therefore, times of year with high $Q$ also could be times when the amount of $C R$ per length of river is substantially greater (e.g., the width of the river is $\geq 2 \times$ greater and CR rates per unit area are $5 \times$ greater leading to a predicted $10 \times$ increase in $C R$ per unit river length). Our results suggest that changes in metabolic rates are not the result of a deeper active water column. Furthermore, Bernot et al. (2010) found rates of GPP ranging from $\sim 0.5$ to $7 \mathrm{mg} \mathrm{O}_{2} \mathrm{~m}^{-2} \mathrm{~d}^{-1}$ and rates of CR from 3 to $8 \mathrm{mg} \mathrm{O}_{2} \mathrm{~m}^{-2} \mathrm{~d}^{-1}$ in 72 shallow streams. The metabolic rates we observed were well within these ranges, indicating that benthic organisms would be capable of metabolizing at rates adequate to explain our results.

Coupling between $\mathrm{Q}$ and $\mathrm{C}$ use has been demonstrated in smaller, agricultural streams in the midwestern USA, a finding that was explained by landuse conditions associated with intensive row-crop agriculture (Griffiths et al. 2012). The lower Mississippi

TABLE 4. Annual metabolic rates for the Mississippi and Chattahoochee Rivers. Analysis of variance suggests that community respiration (CR) and gross primary production (GPP) did not vary significantly between rivers $(p>0.10)$, but net ecosystem production (NEP) was significantly more negative in the Mississippi than in the Chattahoochee River $(p=0.003)$.

\begin{tabular}{|c|c|c|c|c|}
\hline River & Dates & $\mathrm{CR}\left(\mathrm{g} \mathrm{m}^{-2} \mathrm{y}^{-1}\right)$ & GPP $\left(\mathrm{g} \mathrm{m}^{-2} \mathrm{y}^{-1}\right)$ & $\operatorname{NEP}\left(\mathrm{g} \mathrm{m}^{-2} \mathrm{y}^{-1}\right)$ \\
\hline \multirow[t]{2}{*}{ Mississippi } & $\begin{array}{l}1 \text { October 2007- } \\
30 \text { September } 2008\end{array}$ & -1010 & 256 & -754 \\
\hline & $\begin{array}{l}1 \text { October 2009- } \\
30 \text { September } 2010\end{array}$ & -901 & 193 & -708 \\
\hline \multirow[t]{2}{*}{ Chattahoochee } & $\begin{array}{l}1 \text { October 2008- } \\
30 \text { September } 2009\end{array}$ & -847 & 460 & -386 \\
\hline & $\begin{array}{l}1 \text { October 2009- } \\
30 \text { September } 2010\end{array}$ & -567 & 249 & -317 \\
\hline
\end{tabular}


River is characterized by floodplain, row-crop agriculture (Shen et al. 2012), whereas the Chattahoochee is more strongly associated with forested and urban areas (Meyer et al. 2005). These disparities in land use between rivers may cause upstream supply of bioavailable $C$ to differ between rivers and could explain the positive relationship between $\mathrm{CR}$ and $\mathrm{Q}$ in the Mississippi and not in the Chattahoochee (Fig. 5A, C). However, we do not have enough data to test this hypothesis.

\section{Metabolism and seasonality}

Other investigators have documented high values of GPP during periods of low flow. These values are most likely to be related to increases in PAR reaching benthic producers (Young et al. 2008, Marcarelli et al. 2010), thereby stimulating GPP in small streams (e.g., Mulholland et al. 2001, Bernot et al. 2010). GPP was modest and decoupled from PAR in the Mississippi, but GPP was strongly influenced by PAR in the substantially shallower Chattahoochee (potentially indicating the importance of benthic primary producers). $T$ directly influenced $C R$ in the Chattahoochee and Mississippi, but the association was stronger in the Mississippi. PAR only indirectly affected $C R$ via its effect on $\mathrm{T}$ for both rivers (Fig. 7).

Seasonal patterns of metabolism have been demonstrated in other rivers (Table 5). Naiman (1983) observed greater GPP and CR in July than in August and October in an east-central Canadian river. This seasonal difference was of a greater magnitude (9.7 and $66 \times$ greater in July than in October for GPP and $C R$, respectively) than we observed ( $\sim 5$ and $2.5 \times$ greater in July than in October for GPP and CR, respectively). The greater differences found by Naiman (1983) could be a consequence of day lengths at high latitudes and greater seasonal temperature fluctuations in east-central Canada, compared to our study sites in the southeastern USA. In the Kissimmee River, a smaller river in Florida, GPP did not differ substantially between summer and winter, but CR increased $3 \times$ in summer and autumn (Colangelo 2007). At our study sites, the Chattahoochee did not but the Mississippi River did exhibit strong seasonal patterns.

Both rivers were heterotrophic for most of the year, despite a few notable periods of measurable GPP $>0$ and NEP near 0 . In general, observed net heterotrophy supports the prediction of the RCC that upstream subsidies are important in large rivers (Vannote et al. 1980). The importance of downstream heterotrophy has been confirmed for whole-river metabolism measured over shorter periods of time (Minshall et

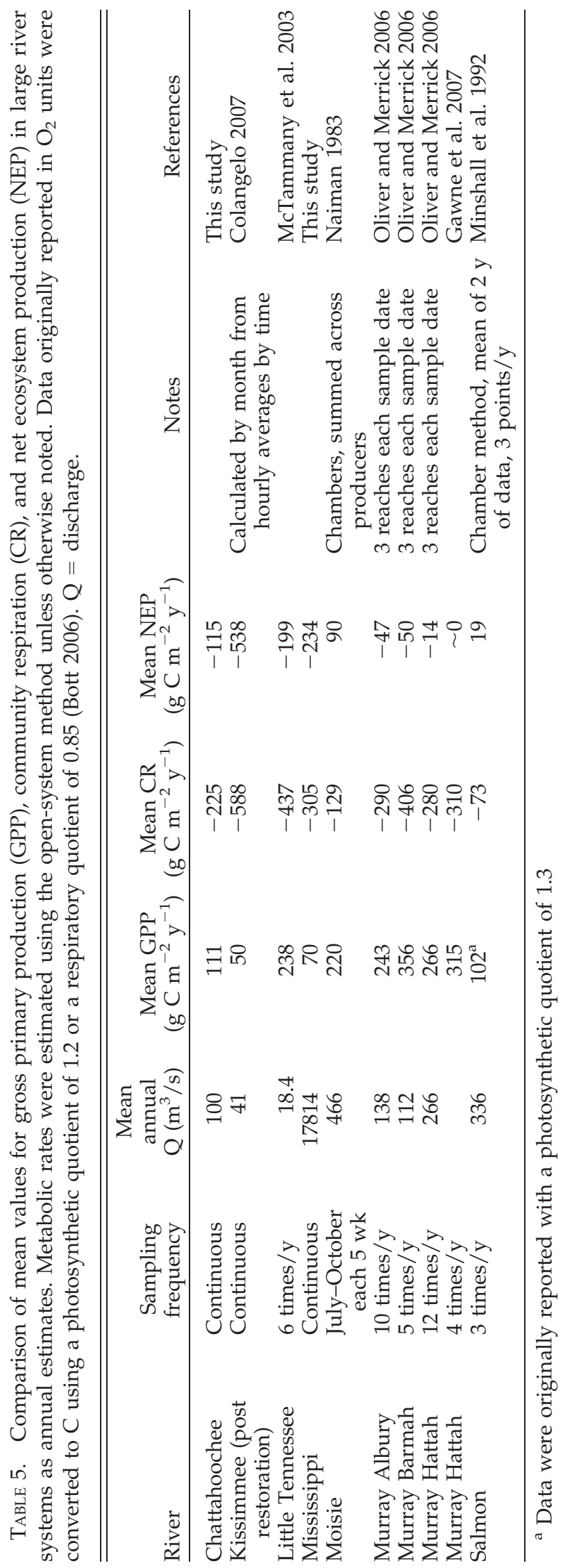


al. 1992, Oliver and Merrick 2006, Collier et al. 2012). Our results also provide some support for the idea that autochthonous production could be an important food source in these large rivers, at least at some times of the year, given that we did regularly detect positive rates of GPP. Food webs of some large rivers are more reliant upon autochthonous $C$ sources than would be expected (Thorp and Delong 2002), and GPP can increase with river size (McTammany et al. 2003). We did not analyze relationships between metabolism and secondary consumer production, but during winter and early spring significant GPP occurred in both rivers. We cannot use our data to estimate the relative importance of GPP in large rivers, but they do not indicate that GPP is unimportant.

Annual rates, sample size, variation, and comparison with other studies

One question that our data allow us to address is the sample size required to estimate annual metabolism accurately in these large rivers. In both rivers, rates of change of metabolism generally were very slow and remained constant over a period of a week. In cases where our ability to model $\mathrm{O}_{2}$ changed abruptly over a week, the changes generally were associated with large changes in Q. Furthermore, analysis of time-lagged correlations using weekly data suggested autocorrelation over $\sim 10 \mathrm{wk}$. Consequently, $\sim 5$ periods would be needed throughout the year to characterize annual estimates. Power analysis of typical 10-wk periods in the Mississippi indicated that 4-to-10 wk were necessary to characterize the mean value within $50 \%$ at a power level of 0.8 and $p<0.05$ using a 2-sample $t$-test. The same analyses on the Chattahoochee suggested that 6-to-8 wk of data are necessary to characterize each 10 -wk period. Weekly variation in rates was small, so measuring on $1 \mathrm{~d} / \mathrm{wk}$ should capture most dynamics. However, data sondes can measure and $\log \mathrm{O}_{2}$ concentrations continuously with modest amounts of drift, so continuous daily measurement over many weeks repeated over all seasons probably would be the most efficient way to yield reasonable estimates of annual production. These data also indicate that spot measurements of other metabolic characteristics, such as nutrient uptake in large rivers (e.g., Dodds et al. 2008, Tank et al. 2008), probably are inadequate to establish annual rates and would be difficult to compare across rivers.

Interannual variation can occur in river metabolism. The patterns were relatively consistent across years in the Mississippi but not in the Chattahoochee. Colangelo (2007) found that annual rates of GPP and
$\mathrm{CR}$ increased over the $5 \mathrm{y}$ following the Kissimmee River restoration corresponding with an increase in autotrophic activity (Colangelo 2007). His results indicate that trends can occur across years. We hypothesize that the largest rivers, such as the Mississippi, integrate such a large area that they are more consistent from year to year than are mediumsized rivers such as the Chattahoochee and the Kissimmee. However, substantially more data are necessary to test this hypothesis.

Whole-ecosystem metabolism in large rivers may be an important component of the global C cycle (Battin et al. 2008), but little is known about the temporal and spatial variation of metabolic patterns (Cole and Caraco 2001, Cole et al. 2007), and little is known about the world's largest rivers other than the amount of $\mathrm{CO}_{2}$ saturation, which can serve as an index of NEP. This value gives little information on relative rates of GPP and CR. Cole and Caraco (2001) estimated a net heterotrophy of $180 \mathrm{~g} \mathrm{C} \mathrm{m}^{-2} \mathrm{y}^{-1}$ for the Hudson River. If we assume a respiratory quotient of 0.85 , and a photosynthetic quotient of 1.2 (Bott 2006) then the NEP of our 2 study rivers (Table 5) bracket the estimate of the Hudson River, driven by covariation of GPP and CR across both rivers.

Published values for river metabolism indicate that our annual rates fall within those measured for other streams and rivers (Bernot et al. 2010, Marcarelli et al. 2011, Collier et al. 2012; Table 5), but our reported rates are lower than the corrected estimates based on mostly short-term whole-system studies published in a meta-analysis of thirty-seven $\geq 5^{\text {th }}$-order rivers (Battin et al. 2008). The only estimates we found of riverine annual NEP that were positive came from chamber studies (Table 5). Substantially more measurements of NEP are needed, but our early exploration of the data based on whole-system measurements suggest that NEP rates vary $>10 \times$ across rivers. The whole-system rate of $C R$ varied less among rivers than did GPP, a result suggesting that much variation in NEP is driven by differences in GPP. Consequently, substantially more data on metabolism of large rivers and factors driving CR and GPP are necessary to determine the rates of in-stream processing.

Our data lead us to hypothesize that, even in large rivers, GPP is important in some seasons. Furthermore, GPP was more important in the mid-sized Chattahoochee than the Mississippi (although with only 2 sites, generalization is difficult). We acknowledge that central-channel methods might underrepresent the autochthonous production associated with side channels or seasonally connected riparian wetlands. More detailed C budgets for the entire flood plain would be required to assess the effects of 
off-channel habitats on $\mathrm{C}$ dynamics and food webs of these larger rivers. In this way, future studies could more strongly link annual metabolism estimates to foodweb energy fluxes in these systems.

\section{Conclusions}

We applied a modeling approach to estimate river metabolism from publicly available data and to monitor temporal changes and natural disturbances to large river systems. Our data suggest that larger rivers are indeed net heterotrophic when viewed over annual time scales, but that there may be times when GPP balances CR. The data from these 2 rivers suggest that frequent recurring measurements of $\mathrm{O}_{2}$ dynamics are necessary to characterize annual metabolic rates. Future research should be done to quantify seasonal variation in whole-ecosystem metabolism of large rivers representative of all biomes across the globe to better understand their contribution to the global $\mathrm{C}$ cycle.

\section{Acknowledgements}

We thank Steven Lawrence of the Georgia Water Science Center and Paul C. Frederick of the Louisiana Water Science Center for providing the data necessary to run this analysis. We also thank Joe Smith for his assistance with statistical analyses and Matt Troia for his contributions towards an earlier version of the manuscript. This is publication 13-384-J from the Kansas Agricultural Experiment Station.

\section{Literature Cited}

Acuña, G. A., I. Muñoz, U. Uehlinger, And S. Sabater. 2004. Flow extremes and benthic organic matter shape the metabolism of a headwater Mediterranean stream. Freshwater Biology 49:960-971.

BARTÓN, K. 2012. Multi-model inference. R Project for Statistical Computing, Vienna, Austria.(Available from: http:/ / cran.r-project.org/web/packages/MuMIn/index. html)

Battin, T. J., L. A. Kaplan, S. Findlay, C. S. Hopkinson, E. Martí, A. I. Packman, J. D. Newbold, and F. Sabater. 2008. Biophysical controls on organic carbon fluxes in fluvial networks. Nature Geoscience 1:95-100.

Battin, T. J., S. Luyssaert, L. A. Kaplan, A. K. Aufdenkampe, A. Richter, And L. J. Tranvik. 2009. The boundless carbon cycle. Nature Geoscience 2:598-600.

Bernot, M. J., D. J. Sobota, R. O. Hall, P. J. Mulholland, W. K. Dodds, J. R. Webster, J. L. Tank, L. R. Ashkenas, L. W. Cooper, C. N. Dahm, S. V. Gregory, N. B. Grimm, S. K. Hamilton, S. L. Johnson, W. H. McDowell, J. L. Meyer, B. Peterson, G. C. Poole, H. M. Valett, C. Arango, J. J. Beaulieu, A. J. Burgin, C. Crenshaw, A. M. Helton, L. Johnson, J. Merriam, B. R. Niederlehner,
J. M. O’Brien, J. D. Potter, R. W. Sheibley, S. M. Thomas, AND K. Wilson. 2010. Inter-regional comparison of landuse effects on stream metabolism. Freshwater Biology 55: 1874-1890.

Bотт, T. L. 2006. Primary productivity and ecosystem respiration. Pages 663-690 in F. R. Hauer and G. A. Lamberti (editors). Methods in stream ecology. $2^{\text {nd }}$ edition. Elsevier, New York.

Bott, T. L., D. Montgomery, J. D. Newbold, D. Arscott, And C. Dow. 2006. Ecosystem metabolism in streams of the Catskill Mountains (Delaware and Hudson River watersheds) and Lower Hudson Valley. Journal of the North American Benthological Society 25:1018-1044.

Burnham, K. P., And D. R. Anderson. 2002. Model selection and multimodel inference: a practical informationtheoretic approach. $2^{\text {nd }}$ edition. Springer-Verlag, New York.

CAde, B. S., And B. R. NoOn. 2003. A gentle introduction to quantile regression for ecologists. Frontiers in Ecology and the Environment 8:412-420.

Churchill, M. A., H. L. Elmore, and R. A. Buckingham. 1962. Prediction of stream reaeration rates. International Journal of Air and Water Pollution 6:467-504.

Colangelo, D. J. 2007. Response of river metabolism to restoration of flow in the Kissimmee River, Florida, USA. Freshwater Biology 52:459-470.

Cole, J. J., And N. F. Caraco. 2001. Carbon in catchments: connecting terrestrial carbon losses with aquatic metabolism. Marine and Freshwater Research 52:101-110.

Cole, J. J., Y. T. Prairie, N. F. Caraco, W. H. McDowell, L. J. Tranvik, R. G. Striegl, C. M. Duarte, P. Kortelainen, J. A. Downing, J. J. Middleburg, and J. Melack. 2007. Plumbing the global carbon cycle: integrating inland waters into the terrestrial carbon budget. Ecosystems 10: 171-184.

Collier, K. J., J. E. Clapcott, I. C. Duggan, D. P. Hamilton, M. Hamer, And R. G. Young. 2012. Spatial variation of structural and functional indicators in a large New Zealand river. River Research and Applications (in press). doi:10.1002/rra.2609

Cox, B. A. 2003. A review of dissolved oxygen modelling techniques for lowland rivers. Science of the Total Environment 314-316:303-334.

Demars, B. O. L., J. R. Manson, J. S. Ólafsson, G. M. Gíslason, R. Gudmundsdóttir, G. Woodward, J. Reiss, D. E. Pichler, J. J. Rasmussen, AND N. Friberg. 2011. Temperature and the metabolic balance of streams. Freshwater Biology 56: 1106-1121.

DodDs, W. K. 2007. Trophic state, eutrophication and nutrient criteria in streams. Trends in Ecology and Evolution 22:669-676.

Dodds, W. K., J. Beaulieu, J. Eichmiller, J. Fischer, N. Franssen, D. Gudder, A. Makinster, M. McCarthy, J. Murdock, AND J. O'BRIEN. 2008. Nitrogen cycling and metabolism in the thalweg of a prairie river. Journal of Geophysical Research 113:G04029.

DodDs, W. K., AND J. J. Cole. 2007. Expanding the concept of trophic state in aquatic ecosystems: it's not just the autotrophs. Aquatic Sciences 69:427-439. 
DodDs, W. K., AND M. R. WHILES. 2004. Quality and quantity of suspended particles in rivers: continent-scale patterns in the United States. Environmental Management 33: 355-367.

Fellows, C. S., J. E. Clapcott, J. W. Udy, S. E. Bunn, B. D. Harch, M. J. Smith, and P. M. Davies. 2006. Benthic metabolism as an indicator of stream ecosystem health. Hydrobiologia 572:71-87.

Gawne, B., C. Merrick, D. G. Williams, G. Rees, R. Oliver, P. Bowen, S. Treadwell, G. Beattie, I. Ellis, and J. Frankenberg. 2007. Patterns of primary and heterotrophic productivity in an arid lowland river. River Research and Applications 23:1070-1087.

Griffiths, N. A., J. L. TANK, T. V. Royer, T. J. WARner, T. C. Frauendorf, E. J. Rosi-Marshall, And M. R. Whiles. 2012. Temporal variation in organic carbon spiraling in Midwestern agricultural streams. Biogeochemistry 108: 149-169.

Holtgrieve, G. W., D. E. Schindler, T. A. Branch, and Z. T. A'MAR. 2010. Simultaneous quantification of aquatic ecosystem metabolism and reaeration using a Bayesian statistical model of oxygen dynamics. Limnology and Oceanography 55:1047-1063.

IsaAcs, W. P., AND A. F. Gaudy. 1968. Atmospheric oxygenation in a simulated stream. American Society of Civil Engineers Journal 94:319-344.

Jassby, A. D., And T. Platt. 1976. Mathematical formulation of the relationship between photosynthesis and light for phytoplankton. Limnology and Oceanography 21: 540-547.

KoenKer, R. 2011. Additive models for quantile regression: model selection and confidence bandaids. Brazilian Journal of Probability and Statistics 25:239-262.

LEWIS, M. E. 2005. Dissolved oxygen. Section 6.2, Chapter A6 in Book 9. U.S. Geological Survey techniques of water resources investigations (draft). US Geological Survey, Reston, Virginia. (Available from: http://pubs.water. usgs.gov/twri9A6/)

Marcarelli, A. M., C. V. Baxter, M. M. Mineau, and R. O. HaLL. 2011. Quantity and quality: unifying food web and ecosystem perspectives on the role of resource subsidies in freshwaters. Ecology 92:1215-1225.

Marcarelli, A. M., R. W. VAn KirK, And C. V. Baxter. 2010. Predicting effects of hydrologic alteration and climate change on ecosystem metabolism in a western U.S. river. Ecological Applications 20:2081-2088.

Marzolf, E. R., P. J. Mulholland, and A. D. Steinman. 1994. Improvements to the diurnal upstream-downstream dissolved oxygen change technique for determining whole-stream metabolism in small streams. Canadian Journal of Fisheries and Aquatic Sciences 51:1591-1594.

Marzolf, E. R., P. J. Mulholland, and A. D. Steinman. 1998. Reply: improvements to the diurnal upstream-downstream oxygen change technique for determining whole-stream metabolism in small streams. Canadian Journal of Fisheries and Aquatic Sciences 55:1786-1787.

McTammany, M. E., E. D. Benfield, and J. R. Webster. 2007. Recovery of stream ecosystem metabolism from histor- ical agriculture. Journal of the North American Benthological Society 26:532-545.

McTammany, M., J. Webster, E. Benfield, and M. Neatrour. 2003. Longitudinal patterns of metabolism in a southern Appalachian river. Journal of the North American Benthological Society 22:359-370.

Meyer, J. L., M. J. Paul, and W. Keith Taulbee. 2005. Stream ecosystem function in urbanizing landscapes. Journal of the North American Benthological Society 24:602-612.

Meyers, L. S., G. Gamst, And A. Guarino. 2006. Applied multivariate research: design and interpretation. Sage Publications, Inc., Thousand Oaks, California.

Minshall, G., R. Petersen, T. L. Bott, C. Cushing, and K. Cummins. 1992. Stream ecosystem dynamics of the Salmon River, Idaho: an $8^{\text {th }}$-order system. Journal of the North American Benthological Society 11:111-137.

Mulholland, P., C. Fellows, J. Tank, N. Grimm, J. R. Webster, S. K. Hamilton, E. Martí, L. Ashkenas, W. B. Bowden, W. K. Dodds, W. H. McDowell, M. J. Paul, and B. J. PETERSON. 2001. Inter-biome comparison of factors controlling stream metabolism. Freshwater Biology 46: 1503-1517.

NAIMAN, R. J. 1983. The annual pattern and spatial distribution of aquatic oxygen metabolism in boreal forest watersheds. Ecological Monographs 53:73-94.

Oliver, R., AND C. Merrick. 2006. Partitioning of river metabolism identifies phytoplankton as a major contributor in the regulated Murray River (Australia). Freshwater Biology 51:1131-1148.

Parkhill, K. L., AND J. S. Gulliver. 1999. Modeling the effect of light on whole-stream respiration. Ecological Modelling 117:333-342.

Reichert, P., U. Uehlinger, AND V. ACuñA. 2009. Estimating stream metabolism from oxygen concentrations: effect of spatial heterogeneity. Journal of Geophysical Research 114:G03016.

Riley, A. J., And W. K. Dodds. 2013. Whole-stream metabolism: strategies for measurement and modeling diel trends of dissolved oxygen. Freshwater Science 32: 56-69.

Roberts, B. J., P. J. Mulholland, And W. R. Hill. 2007. Multiple scales of temporal variability in ecosystem metabolism rates: results from 2 years of continuous monitoring in a forested headwater stream. Ecosystems 10:588-606.

Shen, Y., C. G. Fichot, AND R. Benner. 2012. Floodplain influence on dissolved organic matter composition and export from the Mississippi-Atchafalaya River system to the Gulf of Mexico. Limnology and Oceanography 57: 1149-1160.

SinSABAUGH, R. 1997. Large-scale trends for stream benthic respiration. Journal of the North American Benthological Society 16:119-122.

Tank, J. L., E. J. Rosi-Marshall, M. A. Baker, and R. O. Hall. 2008. Are rivers just big streams? A pulse method to quantify nitrogen demand in a large river. Ecology 89: 2935-2945.

Tank, J. L., E. J. Rosi-Marshall, N. A. Griffiths, S. A. ENTREKIN, AND M. L. STEPHEN. 2010. A review of 
allochthonous organic matter dynamics and metabolism in streams. Journal of the North American Benthological Society 29:118-146.

TANK, J. L., AND J. R. WEBSTER. 1998. Interaction of substrate and nutrient availability on wood biofilm processes in streams. Ecology 79:2168-2179.

Thorp, J. H., And M. D. Delong. 2002. Dominance of autochthonous autotrophic carbon in food webs of heterotrophic rivers. Oikos 96:543-550.

UeHLINGER, U. 2006. Annual cycle and inter-annual variability of gross primary production and ecosystem respiration in a floodprone river during a 15-year period. Freshwater Biology 51:938-950.

Vannote, R. L., G. W. Minshall, K. W. Cummins, J. R. Sedell, And C. E. Cushing. 1980. The river continuum concept. Canadian Journal of Fisheries and Aquatic Sciences 37:130-137.

Webster, J. R., J. B. Wallace, and E. F. Benfield. 1995. Organic processes in streams of the eastern United States. Pages 117-187 in C. E. Cushing, K. W. Cummins, and G. W. Minshall (editors). Ecosystems of the world: 22. River and stream ecosystems. Elsevier, Amsterdam, The Netherlands.
Wetzel, R. G. 2001. Limnology: lake and river ecosystems. $3^{\text {rd }}$ edition. Elsevier Academic Press, Amsterdam, The Netherlands.

Wiley, M. J., L. L. Osborne, AND R. W. Larimore. 1990. Longitudinal structure of an agricultural prairie river system and its relationship to current ecosystem theory. Canadian Journal of Fisheries and Aquatic Sciences 47:373-384.

YounG, R. G., AND A. D. Huryn. 1998. Comment: improvements to the diurnal upstream-downstream dissolved oxygen change technique for determining whole-stream metabolism in small streams. Canadian Journal of Fisheries and Aquatic Sciences 55:1784-1785.

Young, R. G., AND A. D. Huryn. 1999. Effects of land use on stream metabolism and organic matter turnover. Ecological Applications 9:1359-1376.

Young, R. G., C. D. Matthaei, and C. R. Townsend. 2008. Organic matter breakdown and ecosystem metabolism: functional indicators of assessing river ecosystem health. Journal of the North American Benthological Society 27:605-625.

Received: 29 January 2013 Accepted: 19 June 2013 